\title{
Influence of obstetric management on outcome of extremely preterm growth retarded infants
}

\author{
A H P Schaap, H Wolf, H W Bruinse, A L den Ouden, H Smolders-de Haas, \\ I van Ertbruggen, P E Treffers
}

\begin{abstract}
Aim-To describe the long term outcome of extremely preterm growth retarded infants in relation to obstetric management and various perinatal events.

Methods-A cohort study was undertaken in two tertiary care centres with different obstetric management. All infants with fetal growth retardation due to placental insufficiency and resulting in fetal distress at 26 to 32 weeks of gestation, were included for the years 1984-89. Main outcome measures were impairment, disability, or handicap at 2 years corrected age and at school age $\left(4 \frac{1}{2}\right.$ to $101 / 2$ years). Results-One hundred and twenty five $(98 \%)$ were followed up until 2 years corrected age in the outpatient department; $114(90 \%)$ were assessed at school age. Impairments were found in $37 \%$ and disabilities or handicaps in $9 \%$ of the assessed infants, with no difference between centres. All disabled or handicapped children had already been identified by 2 years corrected age.

Conclusions-Disability or handicap were related to neonatal complications (intracerebral haemorrhage or bronchopulmonary dysplasia) and not to obstetric variables, thus making antenatal prediction impossible. The incidence of disability or handicap in these growth retarded infants was comparable with that of other preterm infants.

(Arch Dis Child 1997;77:F95-F99)
\end{abstract}

Keywords: growth retardation; disability; handicap; obstetric variables

Suspected early fetal growth retardation due to placental insufficiency, and causing fetal distress, poses a clinical dilemma. Deciding when to deliver such babies involves balancing the consequences of delivery and attendant neonatal mortality or long term morbidity against the risk of a fetus compromised by nutrient and oxygen deprivation, and the risk of intrauterine death.

We have already reported a comparison of perinatal mortality and short term morbidity in two university hospitals with different management strategies (active or more conservative) for this selected group. ${ }^{1}$ Overall survival was significantly greater at the centre with an active management strategy (centre B). This resulted from a number of intrauterine deaths at centre A, after a decision to abstain from active inter- vention in severely growth retarded fetuses at a very early period of pregnancy. The main reason for this decision was the high estimated risk (about 20\%) of severe handicap. Another observation was that centre A's policy of waiting for signs of obvious fetal distress before delivering a very preterm growth retarded infant was associated with less neonatal morbidity than the more aggressive intervention of centre B. We concluded that long term follow up should determine which management method was preferable with regard to postnatal development of the infant, as disability or handicap might only become evident at an older age.

As far as we are aware, no studies have been published on the long term follow up of early preterm, growth retarded infants due to placental insufficiency. Follow up studies are either related to birthweight or to gestational age, without taking into account the aetiology of preterm delivery. ${ }^{2-7}$

\section{Methods}

Details of the original study population and their perinatal management have been described before. ${ }^{1}$ In brief, all infants of 26 to 32 weeks gestational age who showed signs of fetal distress due to placental insufficiency, between 1984-89, were included in the study. The differences between the two centres were mainly in respect of antenatal management. Centre A undertook conservative management: in cases where the risk of adverse outcome, based on the estimated low fetal weight, was expected to be high ( $50 \%$ mortality and $20 \%$ handicap in surviving infants), ${ }^{8}$ the decision was made to abstain from intervention. In all other cases a caesarean section was performed, but only when a non-stress test was obviously abnormal. Centre B used more active management: a caesarean section was always performed, sometimes without awaiting an obviously abnormal fetal heart rate tracing. All infants who survived the initial hospital stay were included in the study.

FOLLOW UP AT THE OUTPATIENT DEPARTMENT Examinations at the outpatient department of the referral hospitals or by the local paediatrician were scheduled at least until 2 years, corrected for gestational age. Infants were clinically screened at both centres for psychomotor development, neurological disorders, speech, hearing, and visual function. The method was adapted from Egan et al. ${ }^{9}$ Two authors (HS, IE) reviewed all outpatient department records. Together they classified the 2 year old children 
Table 1 Perinatal outcome of the original study population

\begin{tabular}{lcc}
\hline & $\begin{array}{l}\text { Conservative } \\
\text { management } \\
\text { (Centre A) No (\%) }\end{array}$ & $\begin{array}{l}\text { Active management } \\
\text { (Centre B) No (\%) }\end{array}$ \\
\hline $\begin{array}{l}\text { Total } \\
\text { Antenatal } \\
\text { mortality }\end{array}$ & $107(100)$ & $95(100)$ \\
$\begin{array}{l}\text { Total liveborn } \\
\text { Postnatal } \\
\text { mortality }\end{array}$ & $73(32)$ & $95(100)$ \\
$\begin{array}{l}\text { Survivors } \\
\text { ¿ }\end{array}$ & $14(13)$ & $27(28)$ \\
\hline $\mathrm{P}<0.05$. & & $68^{\star}(72)$ \\
\hline
\end{tabular}

as: normal; suspected of disability or handicap; minor handicap; or major handicap according to the WHO classification adapted for 2 year old infants. ${ }^{10}$

In all cases consensus was reached. These results were not known to the investigator (AS) who scored the results of a parental questionnaire.

FOLLOW UP BY QUESTIONNAIRE

In 1994 parents were interviewed by questionnaire. They were asked to assess whether their child had limitations in walking, hand function, hearing, vision, speech-language and comprehension, and whether there was any respiratory impairment. The severity of functional limitation and activity restriction was judged on a five point scale.

The items were categorised according to the International Classification of Impairments, Disabilities, and Handicaps (ICIDH) of the World Health Organisation (WHO). ${ }^{11}$ We regarded a child as impaired if he or she had a disturbance at organ level, or disabled if the impairment or multiplicity of impairments caused loss of function or activity.

We regarded a child as handicapped if he or she had disabilities that caused a social disadvantage. We considered handicap minor if it did not seriously interfere with everyday life and did not require extensive caretaking, and major if it did interfere with everyday life and if it caused dependency or institutionalisation.

When multiple disturbances were present we assigned the child to the most severe category.

To determine whether the outcome changed with time, the group was divided into two periods, one with a follow up of more than $71 / 2$ years and one of less than $7 \frac{1}{2}$ years. We com-

Table 2 Outcome by examination at 2 years corrected age and by questionnaire at the corrected age of $4^{1 / 2}$ through $10^{1 / 2}$ years

\begin{tabular}{|c|c|c|c|}
\hline & $\begin{array}{l}\text { Conservative } \\
\text { management } \\
\text { (Centre A) } \\
\text { No }(\%)\end{array}$ & $\begin{array}{l}\text { Active management } \\
\text { (Centre B) } \\
\text { No }(\%)\end{array}$ & Total No (\%) \\
\hline Included in follow-up & $59(100)$ & $68(100)$ & $127(100)$ \\
\hline Follow-up at 2 years ${ }^{\star}$ & $58(98)$ & $67(99)$ & $125(98)$ \\
\hline Suspect of disability/handicapt & $1(2)$ & $0(0)$ & $1(1)$ \\
\hline Minor handicap $\dagger$ & $1(2)$ & $2(3)$ & $3(2)$ \\
\hline Major handicapt & $3(5)$ & $4(6)$ & $7(6)$ \\
\hline Follow-up by questionnaire ${ }^{\star}$ & $53(90)$ & $61(90)$ & $114(90)$ \\
\hline Impairment $\dagger$ & $18(34)$ & $24(39)$ & $42(37)$ \\
\hline Disability ${ }^{\prime}$ & $1(2)$ & $3(5)$ & $4(3)$ \\
\hline Minor handicap $\dagger$ & $1(2)$ & $2(3)$ & $3(3)$ \\
\hline Major handicapt & $2(4)$ & $1(2)$ & $3(3)$ \\
\hline Normal $\dagger$ & $31(58)$ & $31(51)$ & $62(54)$ \\
\hline
\end{tabular}

$\star$ Percentage of total No survivors.

† Percentage of assessed children. pared the results of scoring at the age of 2 with those of the questionnaire.

Approval for the study was given by the research ethics committees of the two university hospitals.

\section{STATISTICS}

Data were analysed by computer using BMDP statistical software (Los Angeles, USA). Differences between categories were tested for significance using the $\chi^{2}$ test with Yates' correction. Significance was considered at $\mathrm{P}<$ 0.05 . The influence of gestational age, birthweight, sex of the infant, centre, intracerebral haemorrhage (ICH), respiratory distress syndrome (RDS), bronchopulmonary dysplasia (BPD), sepsis and period of follow up on the incidence of disability/handicap was analysed using logistic regression analysis to address the interaction between these factors.

\section{Results}

COMPARISON BETWEEN CENTRE A AND B

Table 1 shows the total study population $(n=202)$, with 34 antenatal deaths at centre A. One hundred and twenty seven children were discharged home alive and were included in the outpatient department follow up programme. Two children were lost to follow up. One hundred and twenty five were followed up at least until the corrected age of 2 (101 in the perinatal centres and 24 by a local paediatrician). No infant died after discharge home. Thirteen out of 127 survivors were lost to follow up at the time of the questionnaire (six from centre A and seven from centre B): two children could not be traced and 11 families did not respond despite repeated requests. Thus $114(90 \%)$ of the surviving children were completely assessed.

The overall outcome of assessed children is shown in table 2. The percentages of disabilities and handicaps in the two centres were similar, but the overall adverse outcome (mortality and disability or handicap) differed significantly: 52/107 (49\%) in centre A compared with 33/95 (35\%) in centre B $(\mathrm{P}<0.05)$.

\section{OUTCOME OF QUESTIONNAIRE}

Table 3 shows the outcome of the questionnaire for the areas of assessment. The highest incidence of handicap was found in neuromotor function, mental development, and language and speech development. Disorders of neuromotor function, mental development, and/or language and speech development were often found in the same child.

All children but one with a disability or handicap at the time of the questionnaire had already been identified at follow up at the age of 2. The exception was a child who was considered disabled according to the questionnaire but was only classified as suspected of disability at the age of 2 . The severity of the disorder changed with time in six children. In three infants handicap was reclassified from major to minor; in the other three a minor handicap was reclassified as disability. Most of these changes were in the area of neuromotor 


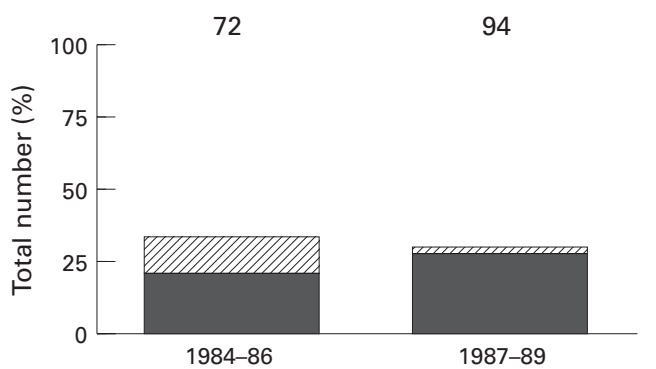

Death $\square$ Disability/handicap

Figure 1 Mortality and disability/handicap for all liveborn infants followed up $(n=166)$, and subdivided for the study. The total number of each subgroup is specified.

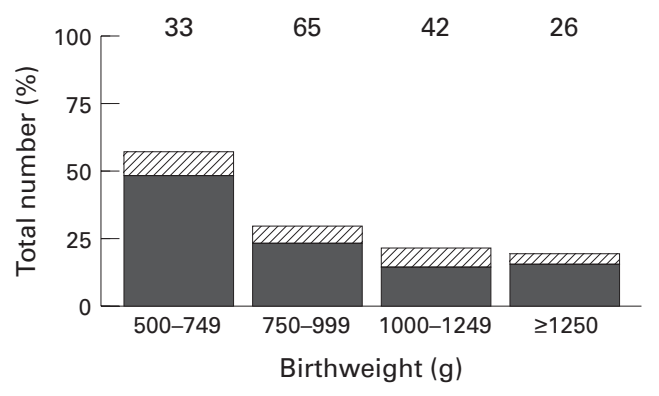

Death $\square$ Disability/handicap

Figure 2 Mortality and disability/handicap in all liveborn infants followed up $(n=166)$, subdivided for birthweight (g). Total number of each subgroup is specified.

function. There was no difference in impairments between the centres according to the questionnaire.

Outpatient clinic data were available for 11 of the 13 non-responders to the questionnaire: eight children were normal, one child had a minor handicap (sensorineural deafness) at the age of 5, and one child had an impairment (chronic obstructive pulmonary disease) at the age of $4 \frac{1}{2}$ years.

Both study periods showed a comparable composite outcome of death and disability or handicap (33\% in the first period vs 30\% in the second period). During the first half of the study, postnatal mortality was lower, although not significantly (13\% vs $28 \%$ ), while disability or handicap in surviving infants was significantly higher (16\% vs $3 \%$ ) (fig 1$)$.

MULTIVARIATE ANALYSIS

Data from 125 children (including 11 nonresponders to the questionnaire but with a fol-

Table 3 Outcome of the questionnaire by area of assessment, in the 114 assessed children

\begin{tabular}{|c|c|c|c|c|c|}
\hline & \multirow[b]{2}{*}{$\begin{array}{l}\text { Impairment } \\
N=42\end{array}$} & \multirow[b]{2}{*}{$\begin{array}{l}\text { Disability } \\
N=4\end{array}$} & \multicolumn{2}{|c|}{ Handicap } & \multirow[b]{2}{*}{$\begin{array}{l}\text { Total } \\
N=52\end{array}$} \\
\hline & & & $\begin{array}{l}\text { Minor } \\
N=3\end{array}$ & $\begin{array}{l}\text { Major } \\
N=3\end{array}$ & \\
\hline \multicolumn{6}{|l|}{ Neuromotor function } \\
\hline Gross & & 2 & 2 & 2 & 5 \\
\hline Fine & 9 & 1 & 2 & 2 & 3 \\
\hline Mental development & & & 2 & 1 & 3 \\
\hline Hearing & 10 & & & & 4 \\
\hline Visual function & 13 & 2 & 1 & & 16 \\
\hline Language and speech function & 5 & 3 & 2 & 2 & 11 \\
\hline Respiratory tract & 6 & & & 1 & 7 \\
\hline
\end{tabular}

Data are presented as percentage of the total number of infants.

Areas of outcome are not mutually exclusive. low up at 2 years) were analysed using logistic regression. The analysis showed that the risk for disability or handicap was increased in the first study period (RR 30.7 (2.4-396)) and in infants with ICH (RR $38.7(2.1-717)$ ) or BPD (RR 11.2 (1.5-83)). Centre, birthweight, gestational age, sex, RDS or sepsis did not contribute significantly to the model.

Figure 2 shows that birthweight relates to mortality and not to disability or handicap.

\section{Discussion}

The need for a functional classification of handicap is increasingly being recognised. ${ }^{2}{ }^{12}$ To optimise the comparability of outcome we adhered to the ICIDH of the WHO, which relates to the consequences of disease. Although school performance can be categorised according to this, we have not reported this item because of the differences in age at follow up and because the need for special education increases proportionately with age. ${ }^{6}{ }^{13}$ Ninety eight per cent of the children were followed up at the corrected age of 2 and $90 \%$ responded to the questionnaire. Tyson et $a l^{14}$ suggested that untraced survivors may have the same likelihood of handicap as those evaluated. Wariyar ${ }^{15}$ reported significantly higher disability rates among those infants who were more difficult to trace, in a $100 \%$ follow up study. Of the 13 non-responders to the questionnaire, only one child was identified at outpatients as having a minor handicap. This made no difference to the disability or handicap rate. The reason for being lost to follow up in our population was not related to the health status of the infant.

The use of a questionnaire could possibly have generated a source of bias. Parents might overreport or underreport disabilities and handicaps in their children. ${ }^{16}$ However, other studies support the assumption that most parents accurately assess their child's current level of functioning. ${ }^{17}{ }^{18}$ Our results show a similar disability or handicap rate $(9 \%)$ at follow up at 2 years, and in the questionnaire at school age, with a change in severity in six children. Therefore, we considered it justified to perform the logistic regression analysis in the 125 infants with a two year follow up examination.

Total mortality (antenatal and postnatal) was lower with active management. The assumption that antenatal selection could lower morbidity, apparent on short term follow up, was not evident on long term follow up. The disability and handicap rates were comparable between the centres and no difference was detected by univariate and multivariate analysis. This resulted in a significantly higher adverse outcome (total mortality and disability or handicap) in centre $\mathrm{A}$, as a consequence of the intrauterine deaths that occurred with the deliberate non-intervention policy. The estimated handicap rate of $20 \%$ expected by centre A was not confirmed.

The total number of impairments by questionnaire was comparable between the centres. It is not clear yet whether the children with impairment suffered similar but less severe brain injuries than the disabled or handicapped 
children. If so, the impairments could be in the area of cognitive and behavioural functions. ${ }^{5} 13192021$

No difference in total disability or handicap rate was detected on follow up at 2 years corrected age and at school age by questionnaire. This agrees with the results of Palfrey et $a l^{2}$ and Levy et al. ${ }^{23}$ Veen et $a l^{2}$ reported a similar rate of major handicap at 2 and 5 years of age, although their data did not refer to the same children and special education was included in the definition of handicap.

At 2 years of age one child was suspected but not confirmed as abnormal. The disabilities and handicaps on examination in the outpatient department and at follow up by questionnaire were attributed to the same children, but were less severe. The less severe outcome at an older age might have been due to the child's development or because the investigation of certain abilities is easier at an older age, or a combination of these factors. ${ }^{24}$

Most children with disability or handicap had a combination of neuromotor function disorder, mental retardation, and language and speech abnormality, which has also been reported by other authors. ${ }^{2325} 26$

In this group of children birthweight and gestational age were associated with mortality ${ }^{1}$ but not related to disability or handicap. Similar findings were reported by Veen et $a l^{2}$ Touwen, ${ }^{27}$ and Scherjon. ${ }^{28}$ On the other hand, Ehrenhaft et al concluded in a review that birthweight was an important factor, although birthweight alone was used to define the study populations. ${ }^{29}$

Some authors have found an increased incidence of neurodevelopmental handicaps among children with abnormal ultrasound images of the brain. ${ }^{28}{ }^{30-33}$ Weisglas et $a l^{34}$ showed a significant relation between abnormal scan and BPD. Our results show an independent influence of BPD as well as ICH on disability/handicap.

In our selected study population disability or handicap were related to neonatal complications and not to gestational age and/or (estimated) birthweight. This explains the unconfirmed antepartum prediction of handicaps or disabilities in centre A.

The overall adverse outcome (mortality and disability or handicap) was comparable between both study periods. Notable is the lower disability or handicap rate in the second half of the study period. This concurs with a previous publication. ${ }^{35}$ This change with time was present in both centres.

As all disabled or handicapped children had already been identified by 2 years corrected age, the disability or handicap rate in the group ascertained in the second period will probably not change with advancing age. Michelsson ${ }^{36}$ has suggested that five year follow up findings remain valid at nine years of follow up.

Concerns have been expressed by many investigators that offering neonatal intensive care to extremely growth retarded infants might result in a higher prevalence of disabilities or handicaps due to an increase in survival. ${ }^{87-39}$
The lower disability or handicap rate in more recent years in our study is reassuring. During this time, ultrasound imaging of the brain became a definitive part of management in both centres. In some patients treatment was discontinued following sonographic detection of severe cerebral abnormalities. Discontinuation of treatment postnatally seemed to be effective in the prevention of disability or handicap, whereas antenatal prediction and selective non-intervention were not.

Published studies on long term follow up in early preterm infants deal with populations selected by birthweight, gestational age, or a combination of both. The specific selection in the present study - namely, growth retardation and fetal distress due to placental insufficiency, as well as the differences in duration of follow up and outcome definitions - make our results not strictly comparable with those of other studies.

The major handicap rate of survivors in a neonatal intensive care unit (NICU) based study is reported as being $10 \% .^{40}{ }^{41}$ Dutch NICU based studies detected $12 \%$ at 1 year of age ${ }^{42}$ and $16 \%$ at 3.6 years of age. ${ }^{43}$ Contrary to expected, ${ }^{8}$ growth retarded infants as selected in our study seem to have a comparable risk of handicap as other preterm infants.

Whether this also holds for intellectual outcome remains to be seen. Hille et $a l^{13}$ reported a higher handicap rate at nine year follow up compared with that at five years, due to an increase in children who entered special education after the age of 5. Further follow up is needed to discover if the non-disabled or non-handicapped children in our population will eventually show a high rate of minor developmental problems.

Although we have selected our patients extremely carefully and have put considerable effort into a uniform classification of neonatal morbidity we could not control for all possible confounding factors. Some differences between the centres or changes during the period of the study may not have been accounted for. We consider that randomisation between an intervention $v s$ a selective non-intervention strategy (accepting fetal death) is unethical. A comparison between centres is therefore the next best solution.

Ninety one per cent of surviving infants in this selected population are not disabled or handicapped at school age. Gestational age and birthweight were associated with mortality but not with disability or handicap. Antenatal prediction and selective non-intervention were not effective in handicap and disability prevention. Disability or handicap is mainly related to neonatal complications (ICH and BPD).

\footnotetext{
1 Schaap AHP, Wolf $\mathrm{H}$, Bruinse HW, de Leeuw R, van Ertbruggen I, Treffers PE. Fetal distress due to placental insufficiency at 26 through 31 weeks: a comparison between an active and a more conservative management. Eur $\mathcal{F}$ Obstet Gynecol Reprod Biol 1996;70:61-8.

2 Veen S, Ens-Dokkum MH, Schreuder AM, VerlooveVanhorick SP, Brand R, Ruys JH. Impairments, disabiliti s, Brand $\mathrm{R}$, Ruys JH. Impairments, disabilities, and handicaps of very preterm and very-low1991:338:33-6.

1991;338:33-6.
3 Johnson A, Townshend P, Yudkin P, Bull D, Wilkinson AR. Functional abilities at age 4 years of children born before 29 weeks of gestation. $B M \mathcal{F}$ 1993;306:1715-18.
} 
4 Pharaoh POD, Stevenson CJ, Cooke RWI, Stevenson RC. Clinical and subclinical deficits at 8 years in a geographically defined cohort of low birthweight infants. Arch Dis Child 1994;70:264-70.

5 Kitchen W, Ford G, Orgill A,Richards A, Astbury J, Lissenden J, et al. Outcome in infants of birth weight 500 to $999 \mathrm{~g}$ : A continuing regional study of 5-year-old survivors. F Pediatr 1987;111:761-6.

6 Escobar GJ, Littenberg B, Petitti DB. Outcome among surviving very low birthweight infants: a meta-analysis. Arch Dis Child 1991;66:204-11

7 Ehrenhaft PM, Wagner JL, Herdman RC. Changing prognosis for very low birthweight infants. Obstet Gynecol 1989;74:528-35.

8 Ruys-Dudok van Heel I, de Leeuw R. Clinical outcome of small for gestational age preterm infants. $\mathcal{F}$ Perinat Med 1989;17:77-83.

9 Egan DF, Illingworth RS, Mac Keith RC. Developmental screening 0-5 years. In: Clinics in Developmental Medicine No 30. London: Spastics International Medical Publica-
tions in association with W. Heinemann Medical Books tions in assoc

10 van Zeben-van der AA TM, Verloove-Vanhorick SP, Brand $\mathrm{R}$, Ruys JH. Morbidity of very low birthweight infants at corrected age of two years in a geological defined population. Lancet 1989;i:253-5.

11 World Health Organisation. International classification of impairments, disabilities, and handicaps. Geneva: World Health Organisation, 1980:207.

12 Saigal S, Rosenbaum P, Stoskopf B, Milner R. Follow-up of onfants 501 to $1,500 \mathrm{gm}$ birthweight delivered to residents of a geographically defined region with perinatal intensive care facilities. F Pediatr 1982;100:606-13.

13 Hille ETM, den Ouden AL, Bauer L, van de Oudenrijn C, Brand R, Verloove-Van horick SP. School performance at nine years of age in very premature and very low birth weight infants: Perinatal risk factors and predictors at five weight infants: Perinatal risk factors and

14 Tyson JE, Laskey RE, Rosenfeld CR, Dowling S, Gant N. An analysis of potential biases in the loss of indigent An analysis of potential biases in the loss of indiger

15 Wariyar UK, Richmond S. Morbidity and preterm delivery: importance of $100 \%$ follow-up. Lancet $1989 ; \mathbf{i}: 387-8$.

16 Gorter KA. Survey methods for the assessment of physical disability among children. Disability Rehab 1993;15:47-51

17 Anton B, Dindia G. Parental perceptions of cognitive abilities of children with cerebral palsy. Psychol Reports 1984;54:987-90.

18 Beckman P. Perceptions of young children with handicaps: a comparison of mothers and program staff. Mental Retard 1984;22:176-81.

19 Kitchen WH, Ford GW, Rickards AL, Lissenden JV, Ryan MM. Children of birth weight $<1000 \mathrm{~g}$ : changing outcome between ages 2 and 5 years. 7 Pediatr 1987;110:283-8.

20 Ross G, Lipper EG, Auld PAM. Social competence and behavior problems in premature children at school age. behavior problems in prem
Pediatrics 1990;86:391-7.

21 Saigal S, Rosenbaum P, Szatanari P, Campbell D. Learning disabilities and school performance in a regional cohort of disabilities and school performance in a regional cohort of extremely low birth weight $(<1000 \mathrm{~g})$ children : a compari-
son with term controls. $\mathcal{F}$ Dev Behav Pediatr 1991;12:294300 .

22 Palfrey JS, Singer JD, Walker DK. Early identification of children's special needs: A study in five metropolitan communities. F Pediatr 1987:111:651-9.

23 Levy SE, Hyman SL. Pediatric assessment of the child with developmental delay. Pediatr Clin North Am 1993;40:46577 .
24 Ross G, Lipper EG, Auld PAM. Consistency and change in the development of premature infants weighing less than 1,501 grams at birth. Pediatrics 1985;76:885-91.

25 Management group of the Oxford region. Register of early childhood impairments. Annual report. 1989. Oxford: John Radcliffe Hospital, 1990:15.

26 Hagberg B, Hagberg G, Olow I, von Wendt L. The changing panorama of cerebral palsy in Sweden. Acta Pediatr Scand 1989;78:283-90.

27 Touwen BCL. De ontwikkeling van zeer prematuur geboren kinderen. Ned Tijdschr Geneeskd 1995;108:170-1.

28 Scherjon SA, Smolders-de Haas H, Kok JH, Zondervan HA. The "brain-sparing" effect: Antenatal cerebral Doppler findings in relation to neurological outcome in very preterm infants. Am 7 Obstet Gynecol 1993;169:169-75.

29 Touwen BCL. Very low birthweight infants. Eur 7 Pediatr 1986;145:460.

30 Graham M, Levene MI, Trounce JQ, Rutter N. Prediction of cerebral palsy in very low birthweight infants: prospective ultrasound study. Lancet 1987;ii:593-6.

31 Hirata T, Epcar JT, Walsh A, Mednick J, Harris M, McGinnis MS, et al. Survival and outcome of infants 501 to 750 gm: a six-year experience. $\mathcal{F}$ Pediatr 1983;102:741-8.

32 Hack M, Fanaroff AA. Changes in the delivery room, care of the extremely small infant $(<750 \mathrm{~g})$ : effects on morbidity and outcome. N Engl F Med 1986;314:660-4.

33 Stewart AL, Thorburn RJ, Hope PL, Goldsmith M, Lipscomb AP, Reynolds EOR. Ultrasound appearance of the brain in very preterm infants and neurodevelopmental outcome at 18 months of age. Arch Dis Child 1983;58:583604 .

34 Weisglas-Kuperus N, Uleman-Vleeschdrager M, Baerts W. Ventricular haemorrhages and hypoxic-ischaemic lesions in preterm infants: neurodevelopmental outcome at $31 / 2$ years. Dev Med Child Neurol 1987;29:623-9.

35 Saigal S, Rosenbaum P, Hattersley B, Milner R. Decreased disability rate among 3-year-old survivors weighing 501 to 1000 grams at birth and born to residents of a geographically defined region from 1981 to 1984 compared with 1977 to 1980 . F Pediatr 1989;114:839-46.

36 Michelsson K, Lindahl E, Parre M, Helenius M. Nine year follow-up of infants weighing $1500 \mathrm{~g}$ or less at birth. Acta follow-up of infants weighing 1

37 Britton SB, Fitzhardinge PM, Ashby S. Is intensive care justified for infants weighing less than $801 \mathrm{gm}$ at birth? $\mathcal{F}$ Pediatr 1981;99:937-43.

38 Chalmers I, Mutch L. Are current trends in perinatal practice associated with an increase or a decrease in handicapping conditions? Lancet $1981 ; \mathbf{i}: 1415$

39 Avery GB. Ethical dilemmas in the treatment of the extremely low birth weight infant. Clin Perinatol 1987;14:361-5.

40 Anonymous. The fate of the baby under $1501 \mathrm{~g}$ at birth. \{Editorial] Lancet 1980;i:461-3.

41 Johnson MA, Macfarlane AJ. Neonatal intensive care: trends in morbidity. Lancet 1988 ;ii: 168 .

42 Fetter WPF, Baerts W, Borst LE. Late morbiditeit bij kinderen met een geboortgewicht van minder dan 1500 gram, geboren in de periode 1979-1983. Ned Tijdschr Geneeskd 1986;130:1143-6.

43 Weisglas-Kuperus N, Baerts W, Sauer PJJ. Early assessment and neurodevelopmental outcome in very low-birthweight infants: implications for pediatric practice. Acta Paediatr 1993;82:449-53. 